\title{
Primary Cardiac Solitary Fibrous Tumors
}

\author{
Shinichi Taguchi, MD, PhD
}

\begin{abstract}
Primary cardiac solitary fibrous tumors were reviewed. They are classified as pericardial tumors. Their incidences are very rare. Only 16 cases were reported in the literature. Basically, surgical treatments are performed. Their prognoses are generally good, although malignant cases are also reported.
\end{abstract}

Keywords: primary cardiac tumors, solitary fibrous tumors, malignancy, CD34

\section{Introduction}

Solitary fibrous tumors (SFTs) originate from mesenchymal cells, and are spindle cell neoplasms. Although they arise in most cases from the pleura, extrapleural SFTs exist. Cardiac SFTs are rare, and are classified as pericardial tumors due to their origin.

Since SFTs mostly originate from pericardium, clinical features are similar to other intrapericardial tumors and are first diagnosed as tumors of unknown etiology. They may cause pericardial symptoms like pericarditis, tamponade, or congestive heart failure. ${ }^{1)}$ Computed tomography (CT) and magnetic resonance imaging (MRI) delineate the tumors, but it is after surgical treatment that the tumors are diagnosed as SFTs.

\section{Classification}

In 1996, the Armed Forces Institute of Pathology (AFIP) classified SFT of the pericardium within benign tumors of fibrous tissue..$^{2)}$ In 2004, the World Health Organization (WHO) classified this tumor as one of the four types of pericardial tumors. ${ }^{3)}$ In 2013, Amano et al. proposed a new classification in which SFTs are classified as

Department of Cardiovascular and Thoracic Surgery, National Defense Medical College, Tokorozawa, Saitama, Japan

Received: June 19, 2015; Accepted: June 22, 2015

Corresponding author: Shinichi Taguchi, MD, PhD. Department of Cardiovascular and Thoracic Surgery, National Defense Medical College, 3-2 Namiki, Tokorozawa, Saitama 359-8513, Japan Email: staguchi@ndmc.ac.jp

(C)2015 The Editorial Committee of Annals of Thoracic and Cardiovascular Surgery. All rights reserved. one of another four types of pericardial tumors and tumorlike pericardial lesions. ${ }^{4)}$ Although cardiac SFTs are rare, these classifications postulate SFTs as one entity.

\section{Incidence}

Out of 63800 cardiovascular operations performed in Japan during 2012, cardiac tumorectomy was performed in only 628 cases. ${ }^{5)}$ Out of these, cardiac SFT reported by myself in 2013 is assumed to be the sole case. $\left.{ }^{6}\right)$

Many kinds of rare cardiac tumors are reported annually in medical journals. ${ }^{7,8)}$ Cardiac SFT is still a tumor which is reported just by finding its existence.

\section{Cases Reported}

There are only 16 cases of primary cardiac SFTs reported in the English literature, to the best of my knowledge (Table 1). 2,6,9-22) Most of them are adult cases with no gender specificity. Sizes of the tumors are relatively large indicating surgical treatment performed after being symptomatic.

The locations of the tumors vary. The origins include all the four cardiac chambers, aortic arch, and pulmonary artery. Since these tumors originate from the pericardium, the cases mentioning no specific origins are described pericardium as their locations in this table.

\section{Surgical Treatment}

Basically the treatments of these tumors are surgical. The cases which are assumed to tolerate surgical interventions are operated on. The symptomatic cases are operated to relieve their symptoms, and non-symptomatic cases to elucidate their tumor types. 


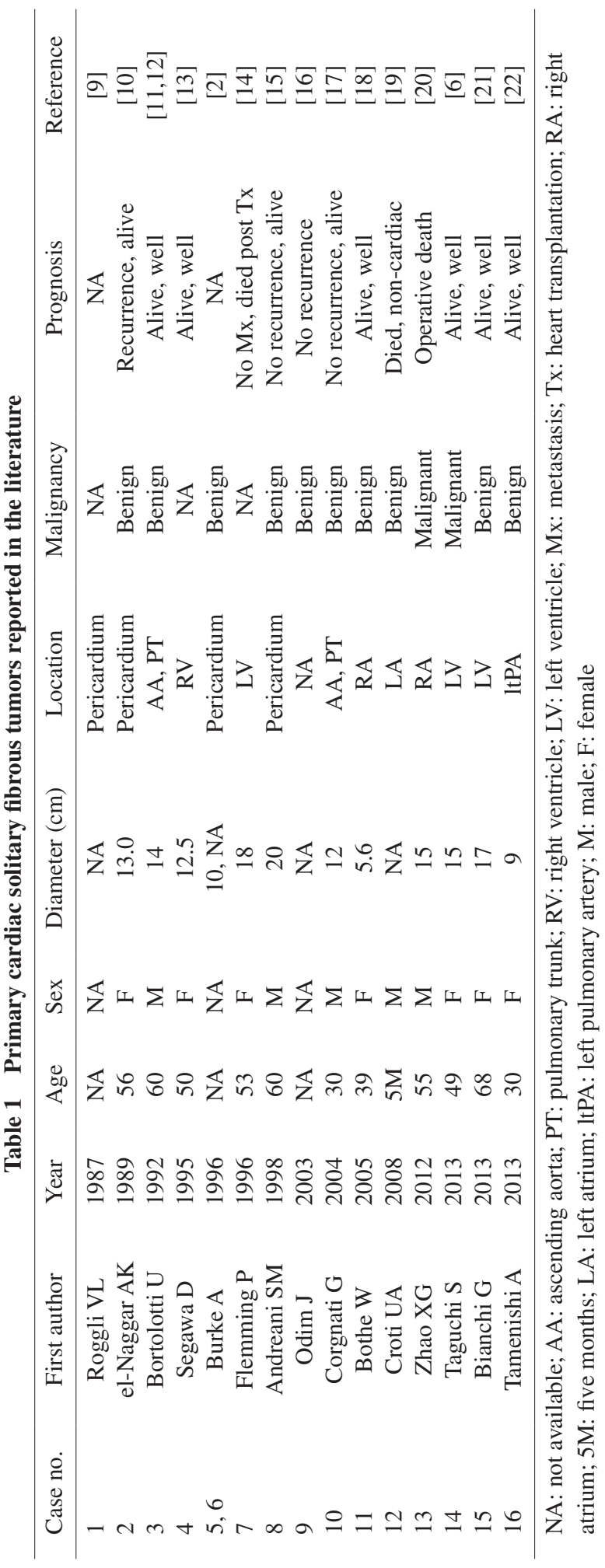

Whether cardiopulmonary bypass (CPB) is used or not, depend on the tumor location, and the hemodynamic stability during the procedure. There are seven cases that mention the usage of CPB. ${ }^{6,13,14,17-20)}$ There are four cases with no usage of CPB. ${ }^{11,15,21,22)}$ Other five cases are unknown.

\section{Prognosis}

Generally, the prognoses of cardiac SFTs are good. 10 of the reported cases are alive or without recurrence. Only two reports indicate the malignancy of the cases. ${ }^{6,20)}$ Most other reported cases are benign. In the malignant cases, hypercellularity and nuclear atypia were positive. They were stained for CD34 which are features of SFTs, ${ }^{20)}$ although negative CD34 is a sign of high-grade malignancy. ${ }^{6}$

Rare malignant examples of SFTs have been reported in the pleura and mediastinum, and analogous tumors of the pericardium have probably been classified as pericardial fibrosarcomas. ${ }^{2,6)}$ Sarcomatous component in malignant SFTs make the diagnosis of this tumor imprecise. ${ }^{23,24)}$

\section{Conclusion}

Primary cardiac SFTs were reviewed. Since they are rare tumors, only 16 cases have been reported in the literature.

\section{Disclosure Statement}

The author has no conflict of interest to declare.

\section{References}

1) Taguchi S, Yozu R. Surgery for primary intrapericardial tumors in adults. J Card Surg 2013; 28: 529-32.

2) Burke A, Virmani R. Classification and incidence of cardiac tumors. Tumors of the heart and great vessels. In: Burke A, Virmani R, eds.; Atlas of tumor pathology, series 3, fascicle 16. Washington, D.C.: Armed Forces Institute of Pathology, 1996; pp 1-11, 75-76.

3) Burke AP, Veinot JP, Loire R, et al. Tumours of the heart. In: Travis WD, Brambilla E, Muller-Hermelink HK, et al. eds.; Pathology and genetics of tumours of the lung, pleura, thymus and heart. Lyon: IARC Press, 2004; pp 249-88.

4) Amano J, Nakayama J, Yoshimura Y, et al. Clinical classification of cardiovascular tumors and tumor-like lesions, and its incidences. Gen Thorac Cardiovasc Surg 2013; 61: 435-47.

5) Masuda M, Kuwano H, Okumura M, et al. Thoracic and cardiovascular surgery in Japan during 2012: annual report by The Japanese Association for Thoracic Surgery. Gen Thorac Cardiovasc Surg 2014; 62: 734-64. 
6) Taguchi S, Mori A, Yamabe K, et al. Malignant solitary fibrous tumor of the left ventricular epicardium. Ann Thorac Surg 2013; 95: 1447-50.

7) Kimura M, Kikuchi C, Takahashi Y, et al. Cardiac myxosarcoma with thoracic spinal metastasis. Gen Thorac Cardiovasc Surg 2014; 62: 441-3.

8) Dell'Amore A, Asadi N, Caroli G, et al. Recurrent primary cardiac osteosarcoma: a case report and literature review. Gen Thorac Cardiovasc Surg 2014; 62: 175-80.

9) Roggli VL, Kolbeck J, Sanfiliippo F, et al. Pathology of human mesothelioma. Etiologic and diagnostic considerations. In: Rosen PP, Fecher RE, eds.; Pathology annual. Part 2 Vol 22. Norwalk: Appleton \& Lange, 1987; pp 91-131.

10) el-Naggar AK, Ro JY, Ayala AG, et al. Localized fibrous tumor of the serosal cavities. Immunohistochemical, electron-microscopic, and flow-cytometric DNA study. Am J Clin Pathol 1989; 92: 561-5.

11) Bortolotti U, Calabrò F, Loy M, et al. Giant intrapericardial solitary fibrous tumor. Ann Thorac Surg 1992; 54: 1219-20.

12) Altavilla G, Blandamura S, Gardiman M, et al. Solitary fibrous tumor of the pericardium. Pathologica 1995; 87: 82-6.

13) Segawa D, Yoshizu H, Haga Y, et al. Successful operation for solitary fibrous tumor of the epicardium. J Thorac Cardiovasc Surg 1995; 109: 1246-8.

14) Flemming $P$, Maschek H, Werner M, et al. Solitary fibrous tumor of the epicardium. Pathologe 1996; 17: 139-44. (in German)
15) Andreani SM, Tavecchio L, Giardini R, et al. Extrapericardial solitary fibrous tumour of the pericardium. Eur J Cardiothorac Surg 1998; 14: 98-100.

16) Odim J, Reehal V, Laks H, et al. Surgical pathology of cardiac tumors. Two decades at an urban institution. Cardiovasc Pathol 2003; 12: 267-70.

17) Corgnati G, Drago S, Bonamini R, et al. Solitary fibrous tumor of the pericardium presenting itself as a pericardial effusion and right ventricular obstruction. J Cardiovasc Surg (Torino) 2004; 45: 393-4.

18) Bothe W, Goebel H, Kunze M, et al. Right atrial solitary fibrous tumor - a new cardiac neoplasm? Interact Cardiovasc Thorac Surg 2005; 4: 396-7.

19) Croti UA, Braile DM, Moscardini AC, et al. Solitary fibrous tumor in a child's heart. Rev Bras Cir Cardiovasc 2008; 23: 139-41.

20) Zhao XG, Wang H, Wang YL, et al. Malignant solitary fibrous tumor of the right atrium. Am J Med Sci 2012; 344: 422-5.

21) Bianchi G, Ferrarini M, Matteucci M, et al. Giant solitary fibrous tumor of the epicardium causing reversible heart failure. Ann Thorac Surg 2013; 96: e49-51.

22) Tamenishi A, Matsumura Y, Okamoto H. Solitary fibrous tumor causing cardiac tamponade. Ann Thorac Surg 2013; 96: 319-21.

23) Chan JK. Solitary fibrous tumour-everywhere, and a diagnosis in vogue. Histopathology 1997; 31: 568-76.

24) Langman G. Solitary fibrous tumor: a pathological enigma and clinical dilemma. J Thorac Dis 2011; 3: 86-7. 